\title{
Antibiografia de uma nação, segundo Fabrizio Gifuni
}

Fabrizio Deriu

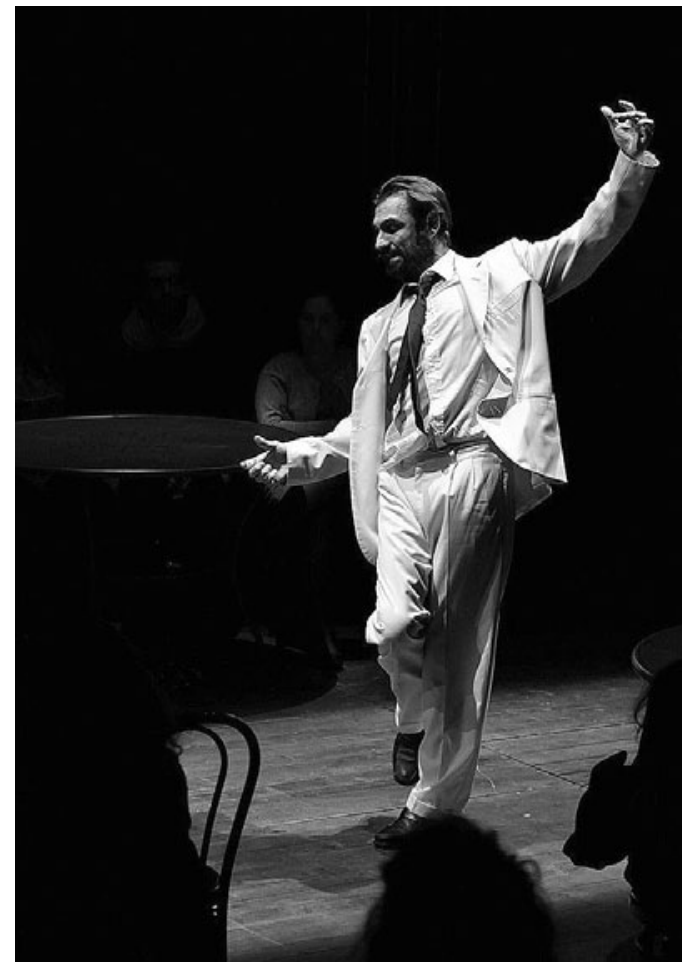

Antibiografia di una nazione (Antibiografia de uma nação) é a designação que abriga um díptico de espectáculos de que é autor e intérprete o actor italiano Fabrizio Gifuni (com a colaboração do saudoso Giuseppe Bertolucci [1947 - 2012] na encenação). 0 primeiro desses dois espectáculos, 'Na specie de cadavere lunghissimo (Uma espécie de cadáver longuíssimo), utilizando textos escolhidos da obra de Pier Paolo Pasolini e um poema do poeta e pintor milanês Giorgio Somalvico, estreou em 2004. 0 segundo, L'ingegner Gadda va alla guerra, o della tragica istoria di Amleto Pirobutirro ( 0 engenheiro Gadda vai à guerra, ou da trágica história de Amleto Pirobutirro), foi apresentado em 2010 e baseava-se em excertos de narrativas do romancista Carlo Emilio Gadda, a que foram acrescentados fragmentos do Hamlet shakespeariano.

A nivel temático o projecto surge, como afirma o próprio Gifuni,

[...] do desejo de organizar um longo conto sobre a transformação do nosso país. Sobre aquilo que fomos, sobre aquilo em que nos tornamos ou sobre aquilo que afinal fomos e somos desde sempre. Para perceber o que aconteceu,
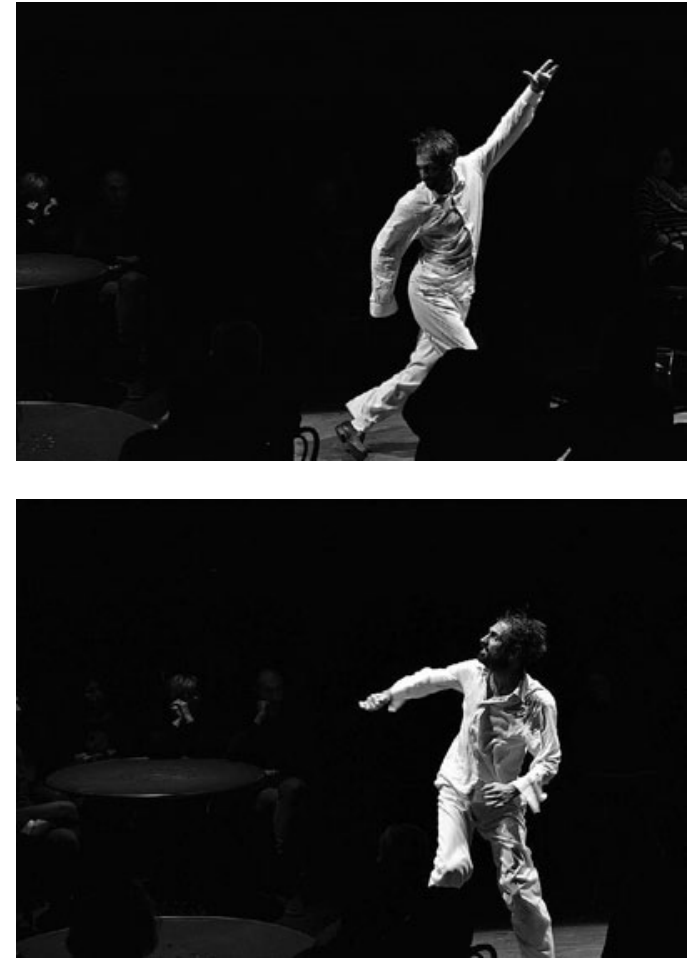

como foi possivel chegar a tudo isto [...]. 0 que resultou, anos volvidos, é um olhar sobre a nossa história do século XX: feroz e inexorável. (Gifuni 2012b: 6)

Um duplo olhar, portanto, a partir de dois autores muito distantes mas que se encontram no espaço comum "[de] um amor furioso pelo seu país, com base nas suas tragédias pessoais e privadas. Dois homens que conquistam a possibilidade de expressar um juizo sobre aquilo que os rodeia, somente depois de se massacrarem a si próprios" (Ibid.: 7)

A nivel formal, as duas produções constituem uma experiência realmente interessante e especial, em que emerge a complexidade e o deslumbramento daquele trabalho cénico que pode ser designado como "elaboração dramatúrgica", entendida em sentido totalmente teatral, como trabalho através do qual o actor "dá corpo" à matéria verbal de partida. Os dois espectáculos apresentam, de facto, alguns elementos originais e que entre si convergem. Quanto à matéria verbal, nenhuma frase dita por Fabrizio Gifuni é escrita por ele, antes é retirada de textos narrativos, poéticos ou ensaísticos dos autores acima referidos; para $<>v$

Uma espécie de cadáver longuissimo, de Fabrizio Gifuni, a partir de textos de Pier Paolo Pasolini e Giorgio Somalvico, enc. Giuseppe Bertolucci, [F.G. - Teatro delle Briciole Solares Fondazione delle Arti, 2004], Teatro della Pergola, 2013 (Fabrizio Gifuni), fot. Filippo Manzini.

Fabrizio Deriu é investigador da Faculdade de Ciências da Comunicação da Universidade de Teramo (Itália) e lecciona disciplinas ligadas à comunicação teatral, metodologia crítica de espectáculos. É especialista no trabalho do actor, especialmente relacionado com o cinema, e em estudos performativos. 


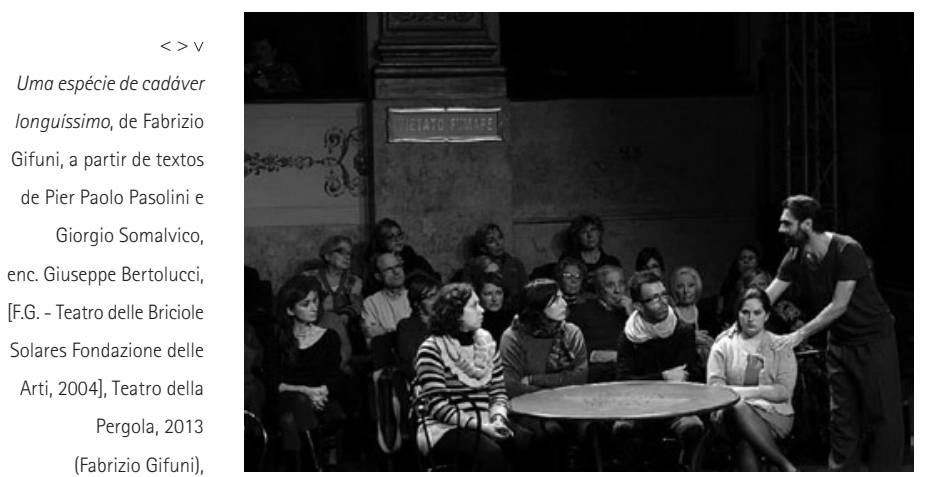

(Fabrizio Gifuni),

fot. Filippo Manzini

além disso, nenhuma das fontes utilizadas é, na sua origem, um texto teatral, ou foi concebido e redigido para uma encenação (excepto os excertos do Hamlet no segundo espectáculo, que, no entanto, surgem como incursões fragmentárias cuidadosamente mimetizadas, a ponto de não serem imediatamente reconheciveis e reconduziveis à obra shakespeariana). Quanto ao género, ambos os espectáculos são classificáveis como monólogos: um só actor em cena, do princípio até ao fim. Como elucidou Bertolucci, ambos apresentam uma estrutura dramatúrgica semelhante: uma primeira parte reflexiva e descritiva, que gradualmente atinge um registo dramático; uma segunda parte onde, pelo contrário, explode abertamente um "enredo grotesco e delirante".

A encenação de Uma espécie de cadáver longuíssimo necessita de um espaço suficientemente amplo e livre para uma dúzia de mesas metálicas, pretas e redondas, pelas quais são distribuídos os espectadores (cerca de seis por cada mesa; enquanto os outros ocupam plateias, camarotes, bancadas, etc., consoante as características arquitectónicas do lugar em que ocorre). Quando o público entra, a sala está iluminada e Gifuni ocupa uma cadeira numa das mesas; assiste calado à chegada dos espectadores e, quando todos estão sentados, deixa passar mais alguns minutos, observando atentamente os seus interlocutores, antes de a acção começar. Depois levanta-se e, dirigindose a um dos espectadores sentado numa das mesas, começa: "Tu dizes que eu tenho saudades da Italieta - a Italieta...". 0 discurso, proposto como se se tratasse de uma conversa que já vai a meio, é uma montagem de textos de Pasolini, inicialmente retirados sobretudo de artigos e ensaios (Escritos corsários, Cartas luteranas), mas a que se acrescentam fragmentos de poemas, de romances e de guiões. Este começo, durante o qual o actor deambula entre as mesas, apresenta-se como um "raciocínio socrático" - conduzido literalmente no meio do público - sobre a transformação da Itália do início dos anos Sessenta até à primeira metade dos anos Setenta do século XX

A parte central, que funciona como transição para a segunda parte, em que o registo muda radicalmente, desenrola-se no fundo do palco, onde se vê uma espécie de camarim (foi ai que o actor mudou de fato). É agora a vez de Os jovens infelizes (espécie de carta redigida poucos meses antes da morte), "em que - observa Gifun - o poeta declara o seu sentimento de condenação daqueles jovens que amara até então, em quem depositara muitas esperanças e por quem se sentia de certo modo atraiçoado" (Gifuni 2011). Logo a seguir, o espectáculo faz uma viragem drástica. Como esclarecem os autores, desencadeia-se, de
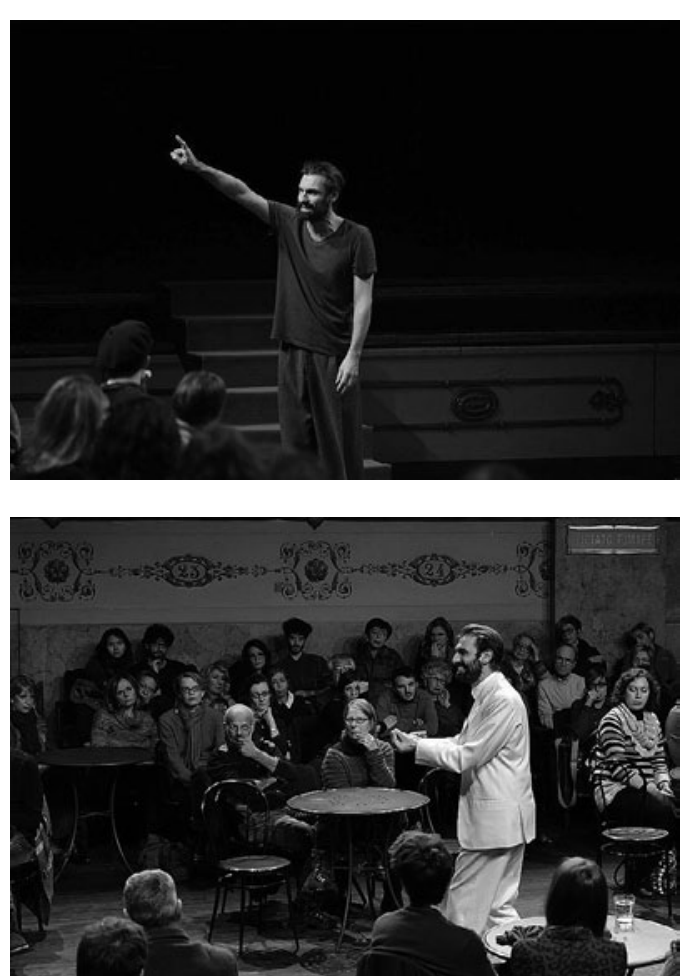

facto, uma "espécie de ágon trágico entre um Pai e um Filho, vivido em cena por um só corpo e uma só voz que [de]ge[ne]ra, sem solução de continuidade, da vítima ao carrasco" (Gifuni in Anón. 2010a). Gifuni, que emprestava a sua voz a Pasolini na primeira parte, torna-se depois no seu assassino; e esta espécie de "contracanto" cabe nos endecassílabos em dialecto romanesco do poema II Pecora (O Pecora) de Giorgio Somalvico. Assiste-se aqui a um "delírio ritmado metricamente" em que se conta a irresponsável e ainda obscura saída nocturna naquele dia 2 de Novembro de 1975, que acabou com a morte de Pier Paolo Pasolini.

Em 0 engenheiro Gadda vai à guerra o espaço cénico é utilizado de modo mais convencional: os espectadores estão sentados na plateia e o actor apresenta-se no palco. 0 cenário resume-se a uma cadeira de madeira. Há, no entanto, um trabalho exigente de luminotecnia, que foca, alternadamente, os dois espaços diferentes em que decorre a acção: um para o Hamlet e o outro para o Gaddus, ou seja, Amleto Pirobutirro. Esclarece Gifuni:

\footnotetext{
A ideia que atravessa o espectáculo é a de reconhecer em Gadda os estigmas de um Hamlet do século XX (dai as citações da famosíssima tragédia): inimigo de um mundo que lhe é inimigo, lucidamente consciente da sua estranheza exactamente como o protagonista de La cognizione del dolore [ 0 conhecimento $d a$ dor], Pirobutirro, em relação à odiada Pastrufazio. (Gifuni in Anón. 2010b)
}

No incipit Gifuni entra em cena arrastando a cadeira, depois traça duas linhas no chão com um giz, um eixo das abscissas e uma das ordenadas que marcam os limites entre os dois espaços referidos, que serão activados alternadamente pelas luzes. Começa, logo, a primeira parte (mais descritiva e reflexiva, como atrás se referiu), cujo texto se compõe de uma selecção de excertos retirados dos gaddianos Diari di guerra e di prigionia (Diários de 

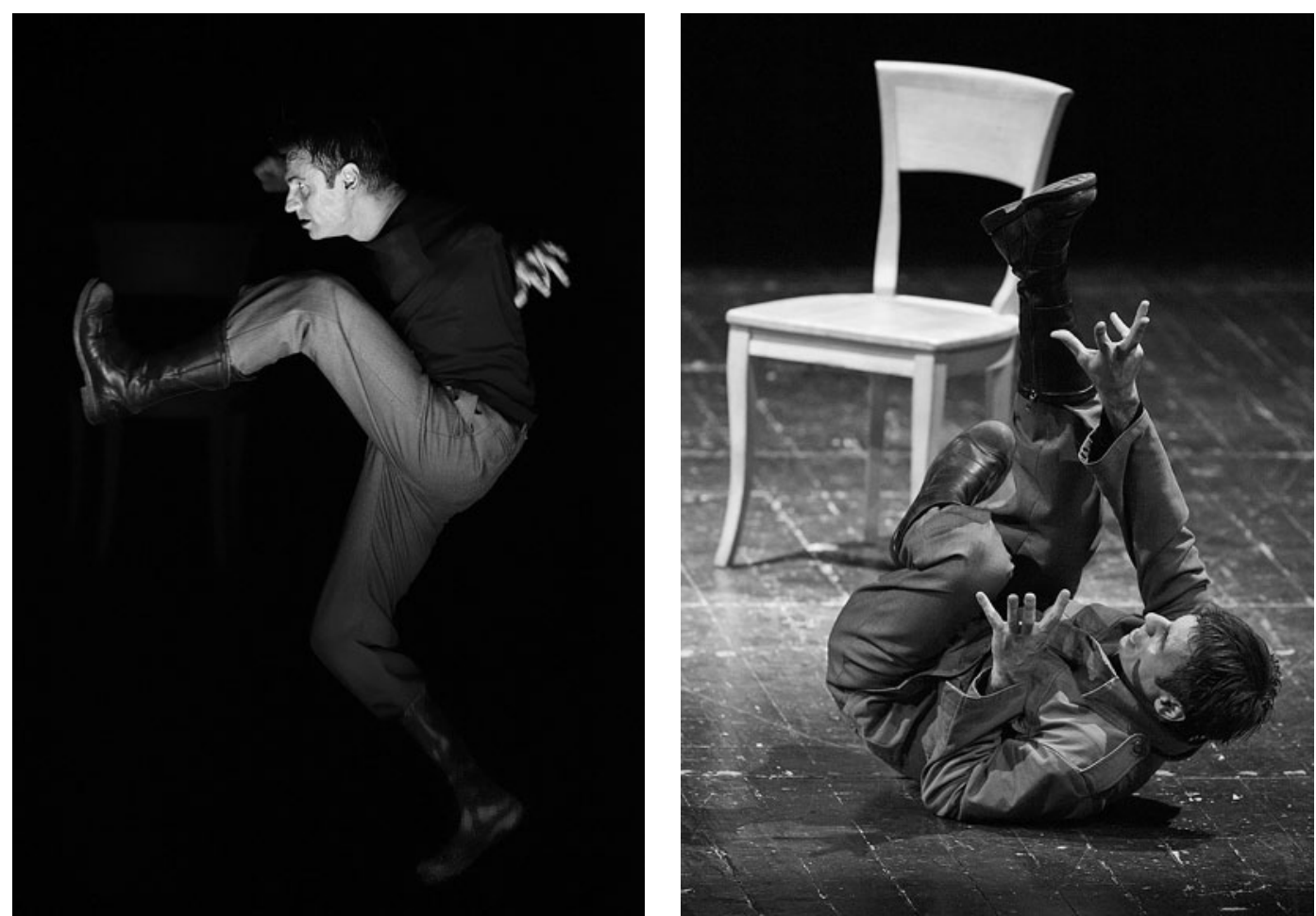

guerra e cativeiro), mas pontuada por breves e fulminantes interferências do Hamlet. A passagem para a segunda parte ("grotesca e delirante") está marcada por uma radical separação mímico-musical: "Arranca uma aterradora conçoneta racista do tempo do fascismo, a que se segue uma breve pantomima tragicómica pelo protagonista. Os dados estão lançados: desaparecer por trás de uma linguagem fora do comum, desencadeando o seu léxico fantasmagórico, será a nova modalidade de comunicar com o mundo. Fingir, como o príncipe de Dinamarca, ser vítima de uma invulgar espécie de loucura será a única maneira de aguentar a sua 'morte em vida'" (Gifuni 2012a: 56).

A segunda parte vale-se, para efeito de contraposição, do fulgurante "tratado de psico-patologia erótica do expresidente do conselho Benito Mussolini", escrito por Gadda em 1945, num fictício mas hilariante florentino antigo e intitulado Eros e Priapo: De furor a cinza. Devido à coincidência entre o tempo representado e o tempo de representação (o espectáculo estreou em 2010 e foi apresentado em muitas cidades italianas nas temporadas seguintes), um aviso à entrada das salas alertava o público, com sarcasmo eficaz, que a peça era "integralmente"

baseada em textos de Shakespeare e Gadda. (Recorde-se que entre 2001-2006 e 2008-2011 quem exerce o mandato como Presidente de Conselho de Ministros em Itália é Silvio Berlusconi...)

0 trabalho cénico e dramatúrgico de Fabrizio Gifuni é extraordinário. De facto, embora permanecendo totalmente inalterado o estatuto literário (ou até literal: não há nenhuma reelaboração nem alteração) dos textos utilizados, o espectáculo revela um domínio excepcional da arte cénica. Não é por acaso que os dois espectáculos, objecto destas anotações, ganharam importantes prémios em Itália. Gadda e Pasolini "oferecem", através de Gifuni, duas peças de um mosaico que reconstrói a hisória em torno do "como" a Itália se tornou o que é hoje, mas para o actor o desafio reside na maneira como dá corpo e som às palavras dos autores:

Porquê reunir as pessoas num teatro para Ihes dizer as palavras de Gadda quando as podem ler comodamente em paz nas suas casas? Para convocar as pessoas é preciso oferecer mais qualquer coisa e o teatro obriga-te a oferecer mais qualquer coisa. [...] Somente dando-Ihe um corpo carne, sangue, humores e porcaria - é possivel realizar este processo de retirar Gadda da página escrita, da dimensão horizontal, e colocá-lo na vertical, fazer ressoar as palavras, libertando os significados poderosos que as palavras encerram. (Gifuni 2012c)

Gifuni desenvolve esse processo através de três operações.

A primeira consiste na "selecção" de trechos a partir da obra completa dos autores escolhidos. Para isso, é determinante a sua fina sensibilidade na individualização daqueles excertos expressivos e poderosos do ponto de vista linguístico, mas também cheios de potencialidades cénicas e performativas (entre as suas muitas acepções, performatividade aponta para a capacidade de a língua escrita captar o magma do pensamento e da comunicação oral para o inscrever no âmbito duma arquitectura literária da qual se possa afastar, ou antes, a ela regressar, pelo gesto e pelas acções vocais e corporais). 0 resultado é muitas vezes uma língua que não é de todo "livresca" (de leitura difícil, como é geralmente a de Gadda), mas dotada de uma enorme "teatralidade".

A segunda operação é representada pela "montagem" dramatúrgica: uma vez seleccionados e retirados do seu contexto original, trata-se de reconfigurar, depois, esses textos de acordo com um determinado projecto, preciso e eficaz. A esse respeito comenta o encenador Giuseppe Bertolucci: "[...] o trabalho, severo e paciente, de Fabrizio com os textos permitiu respeitar a sua integridade e portanto valorizar, perante plateias incrédulas, as
$<>$

O engenheiro Gadda vai à guerra, ou da trágica história de Amleto Pirobutirro, de Fabrizio Gifuni, a partir de textos de Carlo Emilio Gadda e William Shakespeare, enc Giuseppe Bertolucci, F. G. - Teatro delle Briciole Solares Fondazione delle Arti, 2010 (Fabrizio Gifuni), fot. Marco Casell Nirmal. 
O engenheiro Gadda vai à guerra, ou da trágica história de Amleto Pirobutirro, de Fabrizio Gifuni, a partir de textos de Carlo Emilio Gadda e William Shakespeare, enc. Giuseppe Bertolucci, F. G.

- Teatro delle Briciol Solares Fondazione dell Arti, 2010 (Fabrizio Gifuni), fot. Marco Caselli Nirmal. coincidências flagrantes entre passado e presente (em Gadda), bem como a capacidade fulgurante de antecipar o que viria a acontecer (em Pasolini)" (Bertolucci 2012: 14). Bertolucci atribui a um moroso trabalho - longo, lento, rigoroso e cuidado - com os textos o facto de ter conseguido respeitar a "integridade". Mas qual a razão para o fazer e o que poderá ela significar? Em princípio, não é necessário um empenhamento especial ou qualidades extraordinárias para um actor respeitar a integridade de um texto na sua transposição cénica: basta memorizá-lo ad verba, ou seja, palavra a palavra. Mas como todo o (bom) actor sabe, isto não chega para criar um bom espectáculo, e muito menos para fazer justiça ao valor (histórico, literário, poético, político, etc.) dos textos, ainda por cima tratando-se de textos que não foram escritos para o palco.

Bertolucci encaminha-nos, assim, para a terceira e essencial operação, isto é, para aquele aspecto do trabalho teatral invisivel para o público e composto pelo complexo processo através do qual o actor elabora, habilmente, a partitura (física e vocal) da sua interpretação. Dito por outras palavras, aquele trabalho através do qual os "artesãos" do teatro permitem aos signos, que estão no papel, transferirem-se para a cena transformados em acções, gestos, sons, palavras e que nos atraem e ficam impressos na nossa atenção, sensibilidade e memória.

Uma análise mais funda da partitura elaborada para os dois momentos da Antibiografia revela a presença, por um lado, de um leque plural e diversificado de "fontes" actoriais (ecos de grandes actores do teatro italiano do passado recente, como Vittorio Gassman, Paolo Poli, Carmelo Bene; cliché de recitação académica, mas para servir outros efeitos, como a paródia, etc.), e, por outro lado, de invenções originais, graças às quais Gifuni está a construir um modus operandi pessoal e reconhecivel no panorama do teatro contemporâneo italiano, e não só.

Para terminar, é impossível não referir o aspecto "cívico" (quando não propriamente político) dos dois espectáculos, pelo menos assinalando a consciência específica que Gifuni tem do compromisso imprescindivel de "fazer teatro":

Estou cada vez mais convencido que os teatros, hoje mais do que nunca, são o lugar onde se pode travar uma batalha fundamental para os destinos culturais do nosso país. Para além do teatro, não me ocorrem muitos outros lugares, onde uma comunidade possa continuar a reunir-se, livremente, para partilhar um espaço de puro conhecimento emocional. [...] 0 teatro é também um dos últimos lugares onde ainda se pratica a arte da memória. Entendida quer como mnemotécnica (os actores são os últimos depositários desta disciplina), quer como reservatório de uma consciência histórica colectiva. Ė por isso que o teatro, hoje, assusta mais o poder. (Gifuni 2012b: 5 )

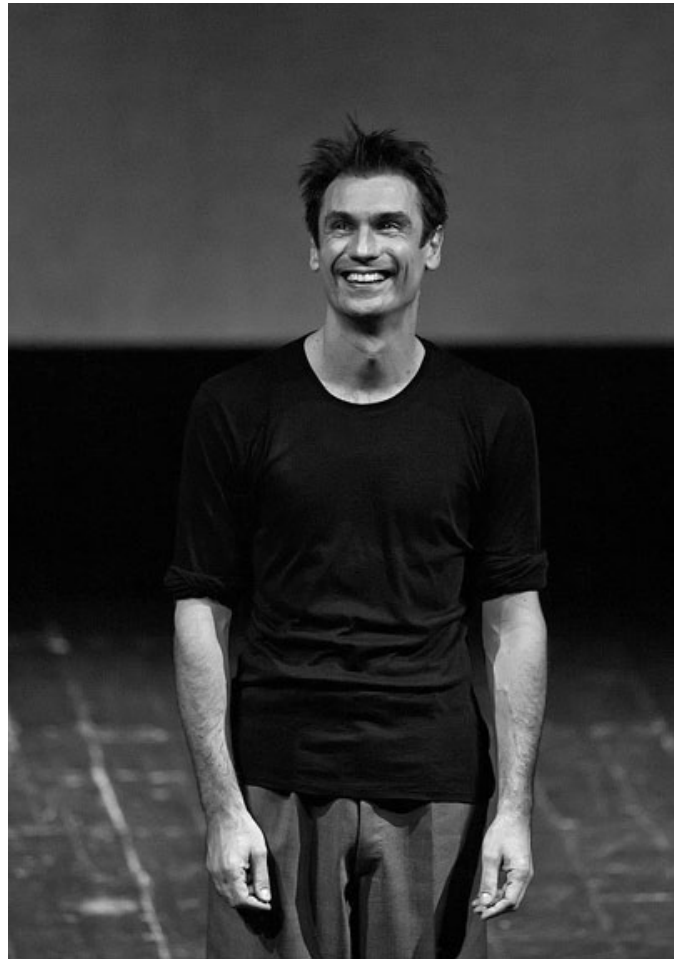

\section{Referências bibliográficas}

Anon. (2010a), Apresentação do espectáculo 'Na specie de cadavere lunghissimo, in Folha de sala da resenha Monografie di scena dedicada a Fabrizio Gifuni, Roma, ETI-Teatro Valle, Novembro.

-- (2010b), Apresentação do espectáculo L'ingegner Gadda va alla guerro o la tragica istoria di Amleto Pirobutirro, in Folha de sala da resenha Monografie di scena, dedicada a Fabrizio Gifuni, Roma, ETI-Teatro Valle, Novembro.

BERTOLUCCI, Giuseppe (2012), I/ percorso di un attore, in F. Gifuni / G. Bertolucci, Gadda e Pasolini:Antibiografia di una nazione (libro+doppio DVD), Roma, Edizioni Minimun Fax, pp. 13-15.

GIFUNI, Fabrizio (2011), Recitare la storia attraverso la poesia, intervista di N. Bultrini, in Poesia, n. 259, aprile 2011 (disponivel no sítio: http://www.fabriziogifuni.it/stampa/interviste/poesia.html).

-- (2012a), L'ingegner Gadda va alla guerra, o la tragica istoria di Amleto Pirobutirro, drammaturgia originale di F. Gifuni (da Carlo Emilio Gadda e William Shakespeare), in F. Gifuni / G. Bertolucci, Gadda e Pasolini: Antibiografia di una nazione (libro+doppio DVD), Roma, Edizioni Minimun Fax, pp. 29-71.

-- (2012b), Gadda, Pasolini e il teatro. Un atto sacrale di conoscenza, in F. Gifuni / G. Bertolucci, Gadda e Pasolini:Antibiografia di una nazione (libro+doppio DVD), Roma, Edizioni Minimun Fax, pp. 5-12.

-- (2012c), Seminario sulla lingua di Gadda al Teatro Valle Occupato 2/8/2011, nei contenuti extra del DVD L'ingegner Gadda va alla guerra..., in F. Gifuni / G. Bertolucci, Gadda e Pasolini:Antibiografia di una nazione (libro+doppio DVD), Roma, Edizioni Minimun Fax GIFUNI, Fabrizio / BERTOLUCCI, Giuseppe (2012), Gadda e Pasolini: Antibiografia di una nazione (libro+doppio DVD), Roma, Edizion Minimun Fax.

Tradução de Sebastiana Fadda 